\title{
IMPLICAÇÕES DAS AVALIAÇÕES EXTERNAS PARA O TRABALHO DOCENTE COLETIVO
}

RENATA CRISTINA OLIVEIRA BARRICHELO CUNHA ANDREZA BARBOSA MARIA JOSÉ DA SILVA FERNANDES

\section{RESUMO}

Este trabalho sistematiza parte dos resultados de uma pesquisa financiada pelo CNPq/Capes, que se propõe a analisar, entre outros aspectos, como as avaliações externas, em especial o Sistema de Avaliação de Rendimento Escolar do Estado de São Paulo (Saresp), estão afetando o planejamento e os encaminhamentos das aulas de trabalho pedagógico coletivo de uma escola estadual paulista no que se refere à discussão do projeto político-pedagógico. Os dados sistematizados derivam da análise de pautas e atas referentes ao trabalho docente coletivo desenvolvido em 2014, bem como de um encontro no qual se discutiram os índices obtidos pela escola nas avaliações externas. Os resultados evidenciam que a preocupação com as metas e índices se sobrepõe à discussão da proposta pedagógica, esvaziando o trabalho docente coletivo de seu sentido articulador e integrador.

PALAVRAS-CHAVE AVALIAÇÃO EXTERNA • ORGANIZAÇÃO DO TRABALHO DOCENTE • GESTÃO PEDAGÓGICA DA ESCOLA • SARESP. 


\section{RESUMEN}

Este trabajo sistematiza parte de los resultados de una investigación financiada por el CNPq/Capes, que se propone analizar, entre otros aspectos, cómo las evaluaciones externas, en especial el Sistema de Avaliação de Rendimento Escolar do Estado de São Paulo (Saresp), están afectando la planificación y los encaminamientos de las clases de trabajo pedagógico colectivo de una escuela estadual paulista en lo que se refiere a la discusión del proyecto político-pedagógico. Los datos sistematizados derivan del análisis de pautas y actas referentes al trabajo docente colectivo desarrollado en 2014, así como de un encuentro en el que se discutieron los índices que la escuela obtuvo en las evaluaciones externas. Los resultados ponen de manifiesto que la preocupación con las metas e índices se superpone a la discusión de la propuesta pedagógica, retirando del trabajo docente colectivo su sentido articulador e integrador.

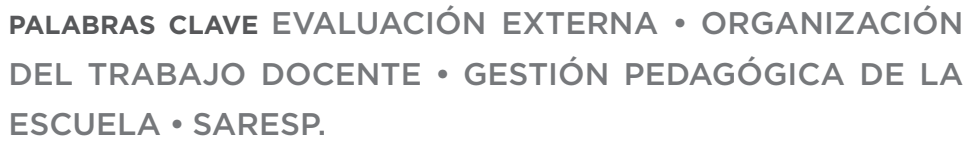

\section{ABSTRACT}

This research systematizes part of the results of a study financed by the CNPq/Capes. It aims to analyze, among other aspects, how external evaluations, especially the Sistema de Avaliação de Rendimento Escolar do Estado de São Paulo [School Performance Evaluation System in the State of São Paulo] (Saresp), affect the planning and the orientation of classes on collective pedagogical work in a state school, and on the discussion of the pedagogical-policy project. The systematized data are derived from the analysis of records and schedules of the collective teaching work developed in 2014, as well as from a meeting in which the indices obtained by the school in external evaluations were discussed. The results show that the concern with the goals and indices overshadows the discussion of the pedagogical proposal, draining the collective teaching work of its articulating and integrating meaning.

KEYWORDS EXTERNAL EVALUATION - TEACHING WORK ORGANIZATION • SCHOOL PEDAGOGICAL MANAGEMENT • SARESP. 


\section{INTRODUÇÃO}

A presente discussão se inscreve no contexto de um projeto de pesquisa financiado pelo Conselho Nacional de Desenvolvimento Científico e Tecnológico (CNPq)/ Coordenação de Aperfeiçoamento de Pessoal de Nível Superior (Capes) (2013-2015), que se propõe a analisar, entre outros aspectos, como as avaliações externas, em especial as relacionadas ao Sistema de Avaliação de Rendimento Escolar do Estado de São Paulo (Saresp), afetam as atividades de planejamento escolar e os encaminhamentos das denominadas aulas de trabalho pedagógico coletivo (ATPC) de uma escola estadual paulista, particularmente em relação à discussão do projeto político-pedagógico (PPP).

Dois pressupostos foram decisivos para a definição deste objeto de pesquisa. O primeiro refere-se ao fato de o PPP constituir-se como ação coletiva, consciente e organizada, com vistas à configuração da singularidade e da particularidade da instituição educativa (VEIGA, 2003). Nesse sentido, o PPP decorre de um processo de planejamento coletivo que tem como elemento fundamental as demandas escolares identificadas por meio de avaliações contínuas e cotidianas. 
Dada sua importância como instrumento de articulação pedagógica e de fortalecimento da identidade da escola, o PPP vai além de um documento programático elaborado pelo grupo de profissionais da escola e se apresenta como a base do trabalho docente coletivo.

O trabalho docente, o segundo pressuposto presente na pesquisa, é definido como "todo ato de realização no processo educativo", ou seja, "que se realiza com a intenção de educar” (OLIVEIRA, 2010, s/p) e que vai além da regência de classe. O trabalho docente coletivo, sobretudo o desenvolvido nas ATPC, pode ser compreendido como espaço/tempo de discussão da intencionalidade do PPP da escola e da organização/articulação do processo educativo.

Nessa perspectiva, entende-se que o trabalho docente coletivo é parte da totalidade do trabalho escolar e tem caráter formativo quando orientado: pelo diálogo e dirigido para a compreensão dos diferentes pontos de vista e da necessidade de ajuda mútua; pela socialização e revisão das práticas individuais e coletivas apoiadas em registros; e pela problematização das teorias que sustentam as práticas. O PPP como instrumento presente na pauta das ATPC representa, portanto, uma plataforma para a revisão dos pontos de vista dos professores, ressignificação das posições assumidas, negociação de perspectivas, construção de consensos provisórios e diálogo entre teoria e experiência (CUNHA; OMETTO, 2013). Compreendendo que a avaliação é parte fundamental do processo educativo, torna-se essencial considerá-la na/para (re)elaboração do PPP, já que ela permite aos profissionais da escola, durante os momentos coletivos, refletir sobre as finalidades do trabalho e o atendimento de seus objetivos. Como produção de sentidos, a avaliação

[...] deve construir os campos sociais de discussão e valoração a respeito dos processos, contextos, produtos, objetivos, procedimentos, estruturas, causalidades, metas de superação, condições de produção das atividades educativas, sentidos e impactos na formação dos cidadãos e na construção da sociedade democrática. (DIAS SOBRINHO, 2008, p. 194) 
No entanto, nas duas últimas décadas, as avaliações elaboradas e aplicadas pelos professores como parte do processo de ensino foram secundarizadas diante das avaliações externas da educação básica, compreendidas como todas aquelas elaboradas fora da escola e sem participação ativa de seus sujeitos que, na maioria das vezes, assumem o trabalho de aplicação e a responsabilização pelos resultados. As avaliações externas, contrariamente às perspectivas democráticas de avaliação como emancipação e condição para o desenvolvimento da autonomia da escola, têm se configurado mais como instrumentos de controle e medida do que enquanto oportunidades de participação e revisão do trabalho realizado pelas redes de ensino e escolas.

Disso decorre que o trabalho docente coletivo, potencialmente pensado como instância de revisão da prática pedagógica e formação docente, passa a ser configurado segundo a lógica da adaptabilidade e da regulação, sendo que as avaliações, constituintes da totalidade escolar, ficam reduzidas à discussão sobre a adequação do currículo ao que é prescrito e cobrado nos testes padronizados, contrariando a lógica do processo educativo.

\section{ENCAMINHAMENTOS METODOLÓGICOS}

A pesquisa vem sendo realizada desde dezembro de 2013 em uma escola da rede pública estadual do interior paulista, que atende a aproximadamente 1.000 alunos do ensino fundamental II e do ensino médio, divididos em três períodos. Segundo caracterização do PPP de 2011, a unidade escolar está inserida numa comunidade carente e muitos moradores e pais de alunos não têm uma profissão definida, o que os obriga a exercer atividades temporárias e informais. Parte das famílias atendidas pela escola participa dos programas sociais do governo federal (como o Bolsa Família), além de contar com programas municipais.

Com ênfase no acompanhamento do trabalho docente coletivo e orientada pela articulação de questões práticas e problemas teóricos, a pesquisa caracteriza-se como uma parceria colaborativa (GIOVANI, 1998) marcada por um processo 
de estudo e investigação que pretende ampliar o conhecimento e a compreensão da realidade escolar e favorecer o desenvolvimento dos vários profissionais. Nesse modelo de pesquisa, os professores da universidade participam na condição de colaboradores dos vários momentos de planejamento e discussão das propostas da escola, não impondo pontos de vista a partir de seus quadros teóricos e da condição de pesquisadores. A relação estabelecida pauta-se na parceria nos diferentes momentos do processo - diagnóstico, problematização e definição de encaminhamentos que façam frente aos problemas identificados no cotidiano escolar.

Tendo em vista os elementos do modelo de pesquisa supracitado, acompanhamos, ao longo de 2014, vários momentos de trabalho docente coletivo com a equipe gestora e professores e, de modo sistemático, as ATPC do ensino médio (EM). Os pesquisadores frequentaram, quinzenalmente, as ATPC do EM, registrando-as em diário de campo e em áudio, para posterior transcrição, bem como outros encontros previstos no calendário da Secretaria da Educação do Estado de São Paulo (SEE-SP), tais como as atividades de planejamento (março), “Dia D” - Autoavaliação Institucional (abril), replanejamento (julho) e "Reflexão do Saresp" (agosto). Também foram acompanhadas, semanalmente, as pautas e atas registradas pelos professores coordenadores referentes a esses encontros.

Para as análises apresentadas neste artigo, recorremos ao diário de campo do período de fevereiro a novembro de 2014, a 20 pautas e 16 atas das ATPC do EM do mesmo período e à transcrição da "Reflexão do Saresp", ocorrida em 22 de agosto de 2014.

A análise deste conjunto de documentos foi orientada pela perspectiva sócio-histórica, admitindo o cotidiano escolar articulado de maneira dialética com a formação social. Nessa perspectiva, compreende-se que as subjetividades dos profissionais da escola estão inscritas em circunstâncias histórico-sociais determinadas. Assim, a educação é assumida como uma trama que vai sendo construída permanentemente a partir da articulação entre histórias pessoais e coletivas situadas em determinado contexto social, portanto, impregnada 
de conteúdo histórico (ROCKWELL; EZPELETA, 2007). Segundo Ferrarotti (2010, p. 44), cada sujeito enquanto conjunto de relações sociais revela-se como "síntese vertical de uma história social". Nesse sentido, o sistema social encontra-se em cada um de "nossos atos, em cada um dos nossos sonhos, delírios, obras, comportamentos. E a história desse sistema está contida por inteiro na história da nossa vida individual" (FERRAROTTI, 2010, p. 44) e na vida dos grupos, portanto, da escola. Essa introjeção do social pelos indivíduos e grupos, de acordo com o autor, não é linear e tampouco determinada mecanicamente. Isso significa que cada ator da escola e o próprio grupo não refletem exatamente o social, mas apropriam-se dele, filtrando-o e traduzindo-o a partir de suas subjetividades.

Quanto ao recorte de análise, justifica-se a atenção ao EM pelo fato deste ciclo não ter atingido, naquela escola, a meta estabelecida pela Secretaria da Educação do Estado de São Paulo (SEE-SP) quanto ao Índice de Desenvolvimento da Educação do Estado de São Paulo (Idesp) de 2013, conforme boletim publicado em 2014. O Idesp, criado em 2008, é calculado a partir dos resultados obtidos pelos alunos na prova do Saresp e dos dados de fluxo escolar (evasão, repetência, distorção idade-série). Vale ressaltar que, quando da implantação do Saresp, em 1996, declarava-se que seu objetivo era servir de referência para a elaboração de políticas públicas e, ao mesmo tempo, orientar o planejamento e a construção do PPP da escola.

Os resultados publicados em 2014 referem-se ao ano anterior. Em 2013 participaram, obrigatoriamente, todas as escolas da rede estadual e todos os alunos do ensino regular matriculados nos $2^{\circ}, 3^{\circ}, 5^{\circ}, 7^{\circ}$ e $9^{\circ}$ anos do ensino fundamental e no $3^{\circ}$ ano do ensino médio. Os componentes curriculares avaliados nesse ano foram Língua Portuguesa e Matemática para todos os anos e História e Geografia para os $7^{\circ}$ e $9^{\circ}$ anos do ensino fundamental e $3^{\mathrm{a}}$ ano do ensino médio (SÃO PAULO, 2013). A Secretaria da Educação do Estado de São Paulo estabelece metas anuais para cada escola, visando à superação do Idesp anterior.

$O$ fato de a escola em questão não ter atingido a meta prevista para o EM impediu que os professores desta etapa 
recebessem o bônus mérito, causando desconforto nos momentos de trabalho docente coletivo e no cotidiano escolar. Desde 2001, com a instituição do bônus mérito pela Lei Complementar n. 909 (SÃO PAULO, 2001), os resultados do Saresp têm servido para determinar o pagamento desse bônus aos profissionais que atuam nas escolas. Em 2008, por meio da Lei Complementar n. 1.078, o bônus mérito passou a ser vinculado ao Idesp e às metas que a Secretaria da Educação do Estado de São Paulo estabelece para cada escola (SÃO PAULO, 2008).

Os professores do ensino fundamental II alcançaram a meta anual e receberam o bônus mérito, mas, como não tiveram avaliação positiva em Língua Portuguesa, já que mais da metade dos alunos do $9^{\circ}$ ano obteve desempenho abaixo do básico na prova do Saresp, a escola passou a ser considerada "prioritária" na Diretoria de Ensino da região. As "escolas prioritárias” são aquelas que não atingem os resultados de aprendizagem esperados e passam a ser monitoradas pelo Núcleo Pedagógico da Diretoria de Ensino. O Plano de Ação dessas escolas, documento elaborado com base nas reflexões da semana de planejamento sobre as prioridades e decisões da escola em relação à análise da aprendizagem dos alunos, passa a ser acompanhado, com apoio técnico à gestão pedagógica mais intenso (SÃO PAULO, 2014). Este acompanhamento objetiva, portanto, mais a adequação à política oficialmente estabelecida do que a (re)elaboração do PPP, uma vez que "qualidade" no contexto de regulação vira sinônimo de resultado e atendimento a metas externamente estabelecidas.

A política implementada pela SEE-SP tem consequência nefasta para o trabalho docente coletivo, pois, ao premiar parte da escola e punir a outra pelos resultados apresentados, fragmenta o processo educativo e fragiliza os professores que passam a não se reconhecer enquanto grupo.

Dessa forma, as análises sobre os efeitos do Saresp no planejamento das ATPC e nas discussões do PPP consideram que o modelo de avaliação externa configura-se como parte de política de regulação característica de determinado contexto social, que marca e limita a organização do trabalho 
pedagógico das escolas. Nessa perspectiva, as determinações e o controle externo, no entanto, não são apropriados pelos professores como dados absolutos, mas assumidos nas suas contradições e traduzidos de acordo com as possibilidades de discussão gestadas no trabalho docente coletivo. Isso porque, como apontado por Rockwell e Ezpeleta (2007, p. 138), a "continuidade no tempo e a permeabilidade através da ambiência social limitam o poder decisório do Estado com relação à realidade de cada escola".

Os fragmentos analisados neste artigo foram selecionados após várias leituras do material empírico e escolhidos por revelarem as contradições entre a presença normativa da SEE-SP e as apropriações dos professores no âmbito de movimentos contínuos de conformação e resistência.

\section{AS AVALIAÇÕES EXTERNAS E AS ESCOLAS: ALGUNS ASPECTOS A SEREM CONSIDERADOS A PARTIR DA BIBLIOGRAFIA}

Considerando-se que a (re)elaboração do PPP, exigência posta pela Lei de Diretrizes e Bases da Educação Nacional, supõe relativa autonomia da escola, de modo a configurar sua própria identidade, é preciso valorizá-la como espaço de diálogo e reflexão coletiva, como instância definidora de critérios para a organização do currículo, das metodologias de ensino e da avaliação (VEIGA, 2013). A identidade da escola, numa perspectiva de gestão democrática, é construída com base na participação ativa da comunidade escolar na discussão de finalidades, objetivos e ações a partir das condições concretas apresentadas. Nos últimos anos, porém, a presença ostensiva dos mecanismos de regulação, com destaque para as avaliações externas, passou a se configurar como formas de controle que dificultam a revisão crítica do trabalho e o fortalecimento das propostas negociadas pela escola, sobressaindo um tipo de organização escolar que secundariza as necessidades escolares a partir da definição pelo grupo de professores e a reorientação do trabalho pedagógico voltado para a melhoria do processo de ensino. As alterações provocadas pelas avaliações externas mudaram o próprio sentido 
de qualidade, como discutem Sousa e Oliveira (2010, p. 818): "usualmente, a ideia de qualidade que vem sendo forjada tem-se restringindo à apreciação do desempenho do aluno, sem que este seja interpretado à luz de condições contextuais, intra e extraescolares".

Ao ter como elemento fundamental de organização pedagógica o cumprimento de metas identificadas como sinônimo de qualidade, ocorre, por parte da escola, uma adaptabilidade aos padrões estabelecidos. Uma dimensão visível da adaptação que interfere diretamente na autonomia da escola e no investimento em seu PPP é o currículo prescrito pela esfera administrativa do sistema, que é usado como condição de premiação (SOUSA, 2003).

O cenário de pressão por resultados mensuráveis, de acordo com a literatura acadêmica, tem revelado que as políticas de avaliação em larga escala não conseguem captar os investimentos e as mudanças ocorridas no cotidiano escolar a partir do trabalho docente coletivo. Isso porque tais dados, que vão além do cumprimento do currículo oficial, não podem ser quantificados por mecanismos padronizados de avaliação. Apesar disso, os resultados decorrentes da implantação do Saresp parecem ter sérios desdobramentos sobre o trabalho docente e o cotidiano das escolas.

Segundo Bonamino e Sousa (2012), as avaliações centralizadas utilizadas para mensurar o desempenho dos alunos, recorrendo aos mesmos parâmetros curriculares que se consideram imprescindíveis a todos os estudantes de uma mesma rede de ensino, podem ter um compromisso com a equiparação de oportunidades e uma discussão mais aprofundada sobre o currículo escolar. No entanto, essas avaliações externas têm consequências para o currículo escolar, pois parecem estar "reforçando o alinhamento, nas escolas e secretarias de educação, entre o currículo ensinado e o currículo avaliado" (BONAMINO; SOUSA, 2012, p. 386), isto é, o uso de provas padronizadas associadas às políticas de responsabilização, principalmente quando envolvem recompensas financeiras, tem aumentado a preocupação das equipes gestoras e dos professores em preparar os alunos para os testes, levando a um estreitamento do currículo escolar. As autoras 
supracitadas consideram que as avaliações em larga escala lidam com uma visão estreita de currículo escolar, uma vez que não levam em conta seus múltiplos objetivos, centrando atenção prioritariamente nos objetivos cognitivos relacionados à leitura e à matemática que podem ser mensurados.

Também Novaes (2014), em pesquisa que discutiu a percepção de professoras da rede estadual paulista a respeito das avaliações externas, destacou que, apesar de não serem totalmente avessas ao Saresp, as professoras entrevistadas não questionavam a maneira como os índices eram produzidos e utilizados e mostravam-se desanimadas por se sentirem obrigadas a mudar a forma de ensinar com vistas a atingir melhores resultados nos testes:

A vinculação da avaliação externa a uma política de bonificação por resultados, diante de um quadro de precarização do trabalho docente, tem desencadeado no âmbito da escola [...] a adoção de práticas questionáveis, como a adequação do currículo à matriz do SARESP, o que tira da escola a autonomia para gerir o currículo, o treinamento para a prova, mediante a manutenção de cursinhos informais e "provões", o que desrespeita o professor e a escola na escolha de seus modos de avaliação, entre outras práticas mais sutis de enquadramento, além dos efeitos sobre a autoestima desses profissionais, já que tal situação vai criando novas subjetividades e maneiras nem sempre claras de se relacionar com a profissão, o que somente serve para aumentar a angústia e a frustração. (NOVAES, 2014, p. 304)

Esses efeitos das avaliações externas, como mecanismos de uma ampla política de responsabilização em vigor em diferentes lugares do mundo, têm repercussões não apenas entre os professores paulistas. Amaro (2013), ao discutir os impactos das avaliações externas em escolas municipais da Baixada Fluminense-RJ, também evidencia o direcionamento do trabalho a partir dos testes padronizados:

[...] isso representa um controle do currículo e, consequentemente, acaba por engessar a ação dos professores em sala de aula para desenvolver determinado conteúdo a ser exigido pelos testes. (AMARO, 2013, p. 47) 
De forma semelhante, a pesquisa realizada por Barbosa e Vieira (2013) na rede estadual de Minas Gerais analisa as implicações das avaliações externas para o trabalho docente naquele estado e também destaca, entre outros fatores, o estreitamento do currículo e a prática de treinar os alunos para resolver questões semelhantes aos testes oficiais. Como consequência dessa ênfase exacerbada nas avaliações, as autoras ressaltam que outros trabalhos desenvolvidos pela escola deixam de ser reconhecidos.

Barbosa e Vieira (2013) ainda apontam que as avaliações externas têm colonizado os tempos, espaços e subjetividades docentes, tanto pela pressão por obter melhores resultados, pela necessidade de preparar os alunos ou planejar atividades voltadas para os testes, quanto pela repercussão da divulgação dos resultados que, por sua vez, tem gerado sentimento de frustração e demanda pela modificação das práticas com vistas a obter melhoria do desempenho.

Hypólito (2010), ao analisar as avaliações externas na rede estadual do Rio Grande do Sul, também confirma que os feitos reguladores alteram as políticas curriculares e o trabalho docente. Quanto a este último aspecto, o autor discute que há uma reestruturação educativa com um direcionamento de um profissionalismo gestado nas práticas individuais e voltado para a obtenção de resultados mensuráveis nas avaliações externas. Para Hypólito, as práticas de trabalho implantadas nas escolas têm relativizado o planejamento político-pedagógico global e o empoderamento do corpo docente.

Apesar da ênfase atribuída às avaliações externas nas reformas educacionais recentes e dos visíveis efeitos da padronização que afeta sobremaneira o cotidiano escolar, Sousa, Maia e Haas (2014), apresentando resultados de pesquisa que considerou os dados do Saresp para 41 escolas paulistas, afirmam que não foi possível verificar uma tendência de evolução dos índices aferidos nas unidades escolares analisadas, identificando-se uma considerável oscilação ao longo dos anos. As autoras ainda destacam que o cumprimento das metas estabelecidas pela SEE-SP não significam necessariamente melhoria do desempenho das escolas, pois, várias 
vezes, essas metas são recalculadas para baixo de um ano para o outro sem que haja mudança qualitativa no trabalho escolar. A partir da pesquisa realizada, as autoras criticam as iniciativas postas pela SEE-SP:

Esses dados elucidam que o cumprimento de metas anuais não necessariamente representa melhoria de desempenho da escola; além disso, nem sempre a premiação recebida pela escola evidencia o aprimoramento de seu desempenho no decorrer dos anos. A focalização na alteração de desempenho anual e a correspondente premiação parecem iniciativas equivocadas, que não induzem a uma melhoria sustentada e qualitativa. (SOUSA; MAIA; HAAS, 2014, p. 203)

A partir do levantamento bibliográfico identifica-se que, em diferentes redes e sistemas de ensino, a regulação faz-se presente e se materializa em um conjunto de ações que influenciam a organização do trabalho pedagógico. Dessa forma, trata-se de um modelo de organização escolar calcado em propostas generalistas que se disseminaram a partir dos anos 1990 no contexto de ampliação da globalização e do neoliberalismo.

\section{AVALIAÇÕES EXTERNAS E A ORGANIZAÇÃO DO TRABALHO DOCENTE COLETIVO NA ESCOLA PESQUISADA}

A análise das pautas das ATPC da escola pesquisada ao longo de 2014 mostra o quanto a preocupação com os resultados do Saresp vai se impondo nos encontros coletivos, desviando a atenção sobre algumas dimensões do PPP da escola.

O PPP exige o diagnóstico e a análise dos resultados educacionais, assim como a proposta pedagógica da escola deve explicitar a concepção, os instrumentos, parâmetros, critérios e formas de avaliação da aprendizagem dos alunos. A avaliação é, portanto, uma das mais importantes dimensões do trabalho educativo da escola e deve servir para (re)orientar a organização pedagógica com vistas à melhoria da qualidade do ensino. $\mathrm{O}$ registro da coordenadora na ata 
da ATPC de 03/04/14 revela que a discussão do grupo aponta para essa compreensão ao expressar:

Tivemos nosso final de ATPC com toda essa angústia e questionamentos que fazemos diariamente. E já concluímos que o primeiro tema para discussão do PPP tem que ser avaliação e recuperação.

Entretanto, a avaliação da aprendizagem realizada sistematicamente pelos professores como parte do processo de ensino tem sido negligenciada nas atividades docentes coletivas a favor das avaliações externas. Chama a atenção, por exemplo, que, do total de 20 ATPC consideradas para análise, oito tinham como ponto de pauta questões relacionadas às formas possíveis de melhorar o desempenho da escola no Saresp ou nos processos avaliativos a ele relacionados, caso da Avaliação da Aprendizagem em Processo, que é de responsabilidade da Coordenadoria de Gestão da Educação Básica (CGEB), da Secretaria da Educação do Estado de São Paulo (SEE-SP). Essa avaliação tem sido divulgada sob a alegação de possuir exclusivamente um caráter diagnóstico, bem como de constituir-se apenas como um instrumento de investigação da aprendizagem dos alunos.

O Quadro 1 sintetiza as pautas das ATPC de 2014, sendo que os pontos relacionados à avaliação do Saresp estão destacados para melhor visualização. 


\begin{tabular}{|c|c|}
\hline 06/02 & $\begin{array}{l}\text { Boas Vindas - Apresentação; mensagem "A escola é uma orquestra"; eleição dos Professores } \\
\text { Representantes de Classe; representantes de classe (alunos); regras e direitos da escola àqueles } \\
\text { que não receberam; disponibilizar orientações CGEB; plano de ensino - entregar até } 24 / 03 \text { (não } \\
\text { se esquecer de incluir os projetos durante o ano); agendamento e preenchimento de ficha para os } \\
\text { espaços e instrumentos eletrônicos da escola; Dia da Pizza - 14/O2; listagem de alunos - não oficial; } \\
\text { alunos em D.P. }\end{array}$ \\
\hline $27 / 02$ & Discussão sobre o trabalho de parceria com as pesquisadoras. \\
\hline 13/03 & Análise e discussão de roteiro para elaboração de PPP - Projeto Político-Pedagógico. \\
\hline $27 / 03$ & $\begin{array}{l}\text { Concluir o perfil das salas; levantamento de alunos com problemas de indisciplina; estudo dos } \\
\text { resultados das Avaliações da Aprendizagem em Processo (AAP). }\end{array}$ \\
\hline $03 / 04$ & $\begin{array}{l}\text { Leitura e discussão do texto "O professor na sociedade contemporânea: um trabalho da contradição", } \\
\text { de Bernard Charlot; discussão sobre os índices do Idesp/2013 da escola. }\end{array}$ \\
\hline 10/04 & $\begin{array}{l}\text { Perfil das salas para Conselho Participativo (pontos positivos, pontos negativos, momento de } \\
\text { aprendizagem que não deu certo); estudo dos conteúdos das diversas disciplinas do ensino médio. }\end{array}$ \\
\hline 08/05 & $\begin{array}{l}\text { Divulgação: ProNEAD - Desafio Educacional Acadêmico - 2014; Rede } 333 / 2014 \text { : Impa cria programa } \\
\text { OBMEP na escola; discussão sobre as fragilidades destacadas na avaliação institucional; reflexão } \\
\text { sobre avaliação e recuperação; pesquisa sobre a inserção das TIC nas escolas públicas. }\end{array}$ \\
\hline 15/05 & Reflexão: O que faz da minha aula diferente? O que define pedagogicamente a escola? \\
\hline 22/05 & Sistematização dos pontos em comum ou princípios de trabalho por disciplina. \\
\hline 29/05 & $\begin{array}{l}\text { Discussão sobre a sistematização das práticas nas diferentes disciplinas; preenchimento de quadro } \\
\text { sobre organização das atividades pedagógicas. }\end{array}$ \\
\hline $17 / 07$ & $\begin{array}{l}\text { Informes gerais; retomada de algumas regras (cópias, agendamentos, etc.); proposta de trabalho para } \\
\text { o segundo semestre enfocando o Saresp; proposta de discussões nas ATPC do segundo semestre; } \\
\text { lanche comunitário. }\end{array}$ \\
\hline 07/08 & $\begin{array}{l}\text { Devolutiva sobre o levantamento das habilidades consideradas prioritárias nas diversas disciplinas; } \\
\text { propostas de ações diversas para atender às dificuldades dos alunos; preparo das atividades do } \\
\text { Saresp que serão desenvolvidas em sala de aula; datas e informações sobre o Provão. }\end{array}$ \\
\hline 15/08 & $\begin{array}{l}\text { Informes: Redes n. 352/2014 - TOEIC - teste de proficiência em inglês, n. 351/2014 - Programa Jovens } \\
\text { Embaixadores, n. } 347 / 2014 \text { - III Seminário de Ciência WEB USP São Carlos, n. 356/2014 - Fórum SM de } \\
\text { Educação; roda de conversa: O que a sua aula tem de diferente? O que define a nossa escola? }\end{array}$ \\
\hline 21/08 & $\begin{array}{l}\text { Vídeo da peça "7 minutos", com Antônio Fagundes; discussão sobre o vídeo; orientação sobre as } \\
\text { carteiras após trabalhos em grupo e sala 11. }\end{array}$ \\
\hline 18/09 & $\begin{array}{l}\text { Análise dos boletins do Saresp/2013; leitura do texto: "Quem deve avaliar? Avaliações internas e } \\
\text { externas", de Gimeno Sacristán; informes: transtornos globais do desenvolvimento (TGD). }\end{array}$ \\
\hline $23 / 10$ & $\begin{array}{l}\text { Participação do prof. de História no grupo sobre Orientação Técnica recebida nessa semana; } \\
\text { participação da professora de Geografia sobre "Projeto Ponte" com alunos do 10 D; ProEMI - parcela } \\
\text { recebida e atualizada em: ar-condicionado, reforma da Sala de Leitura, lousa digital, passeio ao } \\
\text { Catavento (com alunos dos } 10 \text { anos), Projeto Identidade com os } 30 \text { anos; assinatura de revista e } \\
\text { material de química; leitura e discussão da Resolução SE de } 2 / 10 / 14 \text { sobre a reorganização do ensino } \\
\text { fundamental; Saresp/2014. }\end{array}$ \\
\hline $30 / 10$ & $\begin{array}{l}\text { Capacitação dos professores sobre a aplicação do Saresp: vídeo e leitura do manual do aplicador; } \\
\text { organização da escola para esses dias; apreciação e aprovação do Regimento Escolar. }\end{array}$ \\
\hline $16 / 11$ & $\begin{array}{l}\text { Informes: Rede n. } 807 \text { - Questionário "A Ciência e a Tecnologia no mundo atual"; Rede n. } 803 \text { - } \\
\text { Retificação - Credenciamento } 2015 \text { do PEl; vídeos: "O preconceito cega", "O xadrez das cores" e "O } \\
\text { Brasil é de todo brasileiro"; apresentação de coletânea de textos sobre o Dia da Consciência Negra; } \\
\text { elaboração de atividades sobre Consciência Negra. }\end{array}$ \\
\hline $27 / 11$ & Pré-Conselho. \\
\hline $04 / 12$ & Notas e preenchimento de diários. \\
\hline
\end{tabular}

Notas: D.P.= Dependência escolar; $C G E B=$ Coordenadoria de Gestão da Educação Básica; ProNEAD= Projeto Nacional de Educação a Distância; OBMEP= Olimpíada Brasileira de Matemática das Escolas Públicas; TIC= Tecnologias de Informação e Comunicação; TOEIC= Test of English for International Communication; USP= Universidade de São Paulo; ProEMI= Programa Ensino Médio Inovador; PEI= Planejamento Educacional Individualizado.

Fonte: Elaboração das autoras. 
Nos primeiros encontros do ano, além dos combinados de organização para o início do semestre letivo, ficou estabelecido entre os professores da escola e os professores da universidade que as ATPC seriam dedicadas à revisão do PPP, ou seja, à discussão da identidade e da proposta da escola, bem como de seus desafios (desinteresse dos alunos, currículo, necessidade de integração entre disciplinas, inovação nas metodologias de ensino, etc.). A reflexão sobre esses desafios seria apoiada, conforme combinado, na leitura de autores que ajudassem a problematizar as questões das práticas docentes.

A ata da reunião de 03/04/14 evidencia, porém, a dificuldade da escola em cumprir um cronograma de trabalho firmado no grupo a partir de suas necessidades quando o sentimento de urgência para responder aos índices do Saresp começa a se impor:

Neste encontro contamos com a presença dos professores da universidade que haviam solicitado a leitura do texto de Bernard Charlot - "O professor na sociedade contemporânea: um trabalhador da contradição" -, mas em função da publicação dos resultados do IDESP/2014 e do fato da escola ser agora, escola prioritária, a discussão girou em torno disso. Primeiramente fiz uma contextualização desses índices desde 2012, onde o Ensino Médio havia atingido $120 \%$ da meta e o Ensino Fundamental não. No ano passado o Ensino Médio zerou e o Fundamental atingiu 71,43\%, mas em função do número de alunos no nível abaixo do básico a escola entrou para o grupo de escolas prioritárias e contará com a presença de mais um coordenador pedagógico - PCAGP (professora coordenadora de apoio à gestão pedagógica).

No texto mencionado pela professora coordenadora, Charlot (2008, p. 20), entre outras contradições, destaca que a avaliação dos alunos é o "contrapeso lógico da autonomia profissional do docente". Nesse mesmo sentido, pode-se afirmar que as avaliações externas são o contrapeso da (re)elaboração da identidade da escola.

Os resultados do Saresp e suas consequências simbólicas e materiais, tais como tornar-se uma "escola prioritária", 
pressionam a escola, mas há um evidente esforço da professora coordenadora no sentido de tentar ajudar o grupo a valorizar as práticas dos professores e definir parâmetros que sustentem a proposta coletivamente estabelecida. $\mathrm{Na}$ reunião de 15/05/14, ela propõe duas questões: "O que torna minha aula diferente? O que define pedagogicamente a escola?" e registra em ata as manifestações dos professores:

Cada professor relatou "o que torna sua aula diferente". Segue os depoimentos sem a identidade: uso do laboratório de informática para pesquisa; uso de vocabulário mais próximo dos alunos e relações que eles dominam; relação da disciplina com a realidade do aluno, participação das aulas; leitura coletiva com explicação do contexto para facilitar o entendimento; a discussão extrapola o conteúdo, com situações do cotidiano; uso de experiências, sendo que a prática se aproximou mais da teoria, ficou mais participativa e fácil; contextualização da disciplina; trabalho com mapas; retomada do conteúdo, para que o aluno não esqueça daquilo que já foi visto; proximidade do conteúdo com o que o aluno já conhece; aulas mais práticas [...]. $\mathrm{O}$ que define pedagogicamente a escola? Novamente seguem as respostas sem identidade: a horizontalidade das relações; o espaço para discussão; a oportunidade do professor transformar a sua prática; o respeito pelo trabalho do outro; a equipe gestora aposta e confia no professor; a receptividade; o conforto do ambiente que facilita o trabalho; a possibilidade de exercer a essência do ser professor; a equipe gestora próxima dos alunos e professores, sem hierarquia e sim com coleguismo.

A maneira como se organiza o trabalho e a tentativa de um esforço coletivo podem ser interpretadas como exercício de resistência à padronização, conformação e limitação do trabalho ao prescrito no currículo oficial. No entanto, conforme pode ser observado no Quadro 1, a avaliação externa, a despeito do exercício da autonomia, vai ganhando centralidade no cotidiano da escola à medida que se aproxima a data de sua aplicação. Assim, quanto mais próximo à data em que a escola realizará o Saresp, mais esse se torna o 
foco das atenções de todos os envolvidos com a instituição, deixando-se de lado as preocupações já em andamento com relação à organização do trabalho interdisciplinar, como o estudo dos conteúdos das diversas disciplinas do ensino médio (10/04), a pesquisa sobre a inserção das TIC nas escolas públicas (08/05), a sistematização dos pontos em comum ou princípios de trabalho por disciplina (22/05) e a discussão sobre a sistematização das práticas nas diferentes disciplinas (29/05).

A pauta do início do $2^{\circ}$ semestre já indica uma direção mais estreita do trabalho coletivo a partir das definições externas: "Proposta de trabalho para o segundo semestre enfocando o SARESP". A ata de 17/07/14 resume o discutido:

Discutimos sobre a proposta da escola para se trabalhar neste segundo semestre enfocando o SARESP: os professores de todas as disciplinas, quinzenalmente, independente da série, estarão trabalhando questões do SARESP. Não é apenas dar a questão e corrigir com a sala e sim, ensinar os alunos a responderem as questões. As séries que farão SARESP neste ano, isso deverá ser feito semanalmente. Resumindo, é treinar o aluno para o SARESP.

Além da centralidade das avaliações externas, as ATPC também contemplam assuntos de organização da rotina e apresentação de informes da Diretoria de Ensino. A discussão ampliada acerca do PPP e previamente definida como elemento central dos momentos formativos vai esvaziando-se e o trabalho docente coletivo também passa a ser regulado e orientado para o alcance de metas. A própria avaliação a ser elaborada pelos professores da escola sai do domínio da atuação pedagógica dirigida por objetivos específicos e passa a obedecer ao modelo do Saresp - testes com foco em habilidades, conforme registrado em 07/08/14:

Informamos aos professores sobre a data do provão do 3o bimestre que será realizado dia 05/09, e que eles devem encaminhar as questões até dia 22/08/14. Os professores que não entregarem suas questões na data estabelecida, não terão sua disciplina incorporada ao provão. Os professores de Português e Matemática devem elaborar 10 questões, 
relacionadas ao conteúdo trabalhado e os demais professores farão 5 questões, essas questões devem seguir os moldes do SARESP e apresentar habilidades. Neste momento ofertamos o material disponível na escola para que os professores pudessem preparar as atividades. Foi acordado com os professores que primeiro eles realizarão essa primeira etapa das atividades do SARESP, para depois determinar se isso ocorrerá com frequência quinzenal ou semanal. Após esse momento os professores utilizaram o material disponível e prepararam suas atividades.

Fica evidente a forma pela qual o trabalho dos sujeitos da escola torna-se também objeto das avaliações externas, o que vai "influenciar o poder de decisão dos docentes em relação às decisões pedagógicas relativas a seus estudantes, que levem em conta as respectivas condições sociais, econômicas e culturais" (HYPOLITO, 2010, p. 1348).

Para Licínio Lima (2011), as avaliações de larga escala têm se configurado de forma desvinculada da ação pedagógica desenvolvida por professores e alunos para ser algo pensado por especialistas externos a escola. Assim, tendem "a assumir uma natureza estranha e heterônoma” (LIMA, 2011, p. 75). Essa natureza heterônoma é identificada nas palavras da professora coordenadora, por exemplo, quando, em 22/08/14, no dia da "Reflexão do SARESP", lembra aos professores que cotidianamente não se pode esquecer do "conteúdo”, mas que o foco, até os dias 11 e 12/11 quando ocorrerá a aplicação das provas, é "respirar SARESP".

○ foco de agora até 11 e 12 [de novembro] é respirar SARESP, só que a gente não pode esquecer (não é esquecer conteúdo), não é isso que a gente quer, que o SARESP está atrelado ao conteúdo, e é o conteúdo de vocês que é cobrado, em um nível maior, ou menor, mas é o conteúdo, então não é esquecer o conteúdo. [...] Esse trabalho de um espaço da aula, um dia da semana, um dia a cada quinze dias, duas aulas na semana, de fazer atividades voltadas para o SARESP, esse momento a gente já está fazendo na própria ATPC e a gente vai continuar com isso. Nós vamos fazer aquele "intensivão" ainda com os alunos. 
Considerando-se que o ano letivo legal corresponde a 200 dias, os professores da escola terão comprometido mais de $40 \%$ da carga total (82 dias) com atividades de preparação para a avaliação externa: "um dia da semana, um dia a cada quinze dias, duas aulas na semana, de fazer atividades voltadas para o SARESP". Durante esse período, grande parte das ATPC é destinada ao Saresp. Sobre isso, Hypolito (2010, p. 1346), pontua que:

Nesse profissionalismo não há muito espaço para um au-
mento de autonomia. O que tem ocorrido é que o controle
sobre os fins sociais e políticos da educação - as defini-
cões sobre currículo e programas, sobre o que e como
ensinar - tem sido, cada vez mais, transferido das profes-
soras para o controle dos gestores, dos políticos e dos
interesses econômicos mais amplos.

A diretora, assim como a professora coordenadora, também tem que administrar a tensão da pressão por resultados, a contradição entre confiar e cobrar, como se pode observar no trecho da mesma ATPC:

Eu nunca deixei de acreditar que eles [os alunos] são capazes de aprender, porque eles têm condições de aprender, eu sempre falei isso: que se eu não acreditar nisso, eu fecho esse caderninho e vou embora agora, eu vou embora agora [...]. Então, nós temos agora o mês, o "tudo", não "o tudo ou nada", não tem a opção do "nada", é o "tudo ou o tudo", e a gente vai cobrar, eu estou sendo cobrada, nós vamos cobrar.

Essa tensão sofrida pela gestão da escola por conta do advento das avaliações externas é evidenciada também na dissertação de Marcos Lima (2011), que analisou os impactos dos testes padronizados sobre a identidade dos diretores de escolas de ensino fundamental do município de Contagem - MG. $\mathrm{Na}$ pesquisa, o autor identificou que as avaliações externas agem como força modeladora das escolas, pressionando-as a assumir valores próprios do mercado. Nesse cenário, o diretor é pressionado para exigir maior desempenho dos professores para dar conta dos resultados exigidos. Talvez por isso, esse trabalho também aponte que os diretores de escola se mostram 
mais propensos a aceitar as avaliações externas se comparados aos professores, sujeitos sobre os quais recaem, no microcotidiano, as cobranças pela obtenção de resultados favoráveis.

De forma semelhante, Carvalho, Oliveira e Lima (2014), ao discutirem os desafios e demandas da gestão escolar diante das avaliações externas no Rio de Janeiro, destacam que o excesso de avaliações que atingem as escolas tem sobrecarregado a gestão à medida que aumentam as demandas burocráticas. As autoras afirmam ainda ser necessário repensar a preparação de diretores e coordenadores escolares para lidarem com as novas demandas trazidas pelas avaliações, como a capacidade de ler e interpretar índices e resultados e a necessidade de criar um clima escolar favorável diante da tensão gerada pela cobrança por resultados. Dessa forma, como discutido por Hypólito (2010), a reestruturação educativa posta pelos sistemas de avaliação forja novos modelos de gestão baseados não no poder discricionário, mas sim na ação individualizada articulada a resultados.

Assim, como nas palavras da diretora da escola, entre o "nada", o "tudo", o "tudo ou nada" e o "tudo ou tudo", os professores se perguntam por que os alunos não se saem bem no Saresp e a professora coordenadora sistematiza na ata de 18/09/14 algumas das hipóteses levantadas:

[...] as formas de abordagem dos assuntos [no SARESP] nem sempre são as mesmas utilizadas pelos professores e os alunos, na maioria das vezes, não conseguem fazer a relação entre a forma que o professor trabalhou e a maneira como é abordado na avaliação do SARESP; apenas preparar os alunos para a prova nem sempre dará resultados, pois a questão é a assimilação dos conteúdos que nem sempre se dá a contento; se compararmos os índices da escola com os da Diretoria ou Estado, percebemos que mais de 50\% [das escolas] também se apresentam no nível abaixo do básico em Matemática, isso nos mostra que a maioria não está aprendendo nesse sistema estabelecido pela SEE, indicando-nos que algo precisa mudar; em São Paulo, há uma escola piloto dessa proposta da SEE, que também não atingiu o índice: será que ninguém percebe que isso está errado? 
Os professores questionam a dificuldade de articular o que é solicitado no exame ao conteúdo específico de cada disciplina. Corroborando a afirmação de Bonamino e Souza (2012), a lógica das avaliações externas tem provocado alterações no currículo da escola, pois os professores ficam tentando ajustar-se às metas da SEE-SP, sem considerar quem são os alunos e as condições apresentadas para aprendizagem.

Essa análise pode ser apoiada ainda nas considerações feitas por Licínio Lima $(2011,2012)$, que discute que essas políticas de avaliação em larga escala fazem parte do quadro de racionalização da gestão da educação que vem se configurando de forma extremamente burocratizada. Para esse autor (LIMA, 2011, p. 77), a "avaliação hiperburocrática" tem se pautado na estandartização dos resultados, exterioridade e distância da escola e dos sujeitos nela envolvidos. Essas formas de avaliação desvalorizam os processos que não podem ser mensurados, controlando o trabalho pedagógico e instaurando a competitividade no lugar do trabalho coletivo:

Tornou-se possível uma vigilância sistemática, segundo categorias tipificadas a priori, e unilateralmente impostas, que modela as realidades escolares, controlam tempos e espaços, generalizam metodologias e processos de trabaIho, favorecem a padronização e a mensuração, bem como a comparação automática de processos e resultados. A autonomia dos profissionais, a colegialidade e o trabalho cooperativo tendem a se afastar por lógicas de competitividade e de individualização que, ao invés, podem favorecer o isolamento dos professores. (LIMA, L. 2012, p. 148)

Análise semelhante também foi tecida por Ball (2002), que situava essas políticas no quadro de gerencialismo e performatividade que tem afetado a educação, destacando que a ênfase no desempenho dada pelas políticas mais recentes vem contribuindo para construir uma escola do espetáculo.

No entanto, acompanhando o cotidiano da escola e em conversas informais na sala dos professores, posteriormente registradas em diário de campo, foi possível constatar que, apesar da pressão exercida pelos mecanismos de avaliação externa, a escola trava uma luta contra o estreitamento do 
currículo, buscando alternativas pedagógicas para o trabalho em sala de aula. Nas atividades cotidianas, os professores organizavam aulas que envolviam jogos com regras na disciplina de Matemática; projetos de leitura na Sala de Leitura com supervisão das professoras de Língua Portuguesa; produção de fanzines nas aulas de Filosofia; projetos interdisciplinares que contemplavam temas do cotidiano; organização de Feira Cultural que promoveu a expressão dos conhecimentos científicos e culturais dos alunos. Cabe destacar, porém, que essas alternativas de trabalho significativas e de autoria coletiva dos professores, que informam as escolhas pedagógicas e definem a identidade da escola no PPP, não compunham as pautas das ATPC, sendo negociadas num claro processo de microrregulação, durante os encontros na sala dos professores e no dia a dia com os alunos. As ATPC como momentos formais de trabalho docente coletivo e voltados para a discussão do PPP da escola foram, ao longo do ano, afastando-se dos propósitos de valorização e autonomia escolar e servindo ao ajuste previsto pelo Saresp. Essa é uma evidente contradição.

Importante destacar que, mesmo subordinados às regras da SEE-SP, alguns professores mantêm uma visão extremamente crítica sobre o papel exercido pela avaliação externa no trabalho desenvolvido pela escola, como é o caso de um professor que fez a seguinte análise no dia da "Reflexão do SARESP":

Nós estamos fazendo um trabalho e a forma como a gente rege nosso trabalho eu acho que não vai ao encontro do que a Secretaria espera de nós. Aí eu acho que a gente tem que ter, como educadores, o bom senso de entender o que a Secretaria quer, o que de fato significa esta teoria das competências e habilidades, porque essa escola se esforça, tem todo um trabalho [...]. Assim: fizemos tudo bonitinho e estamos fazendo, aí chega lá na hora da prova [...]. O quanto eu segui a cartilha? Mas qual é a consequência disso? A pedagogia das competências ali é o que forma nosso aluno o mais frio possível, é o que forma nem o operário desqualificado, e o setor do homem mais cauterizado e precarizado. Então, essa é uma questão muito complexa, que a gente nunca vai conseguir resolver em um lugar fechado, mas acho importante ter essa consciência porque, para chegar no fim do ano 
e jogar tudo por água abaixo, aí não é legal [...]. Acho que hoje, depois de alguns anos, os professores já perceberam, praticamente, que esse sistema que a Secretaria coloca, que cobra, e cobra na prática do nosso trabalho, já é consciência para todo mundo de que é "furada", é um sistema falido. Nós somos fracos para tentarmos reverter isso, por muitas questões e coisas. Agora, esse sentimento de que a coisa vai de nada a lugar nenhum, todos nós já aprendemos isso, e quando a gente briga por uma questão de bom senso é um trabalho de heróis, verdadeiros heróis.

No posicionamento do professor fica evidente a clareza de que há uma grande diferença entre a concepção de educação adotada pela SEE-SP (não resultante da participação coletiva) e aquela discutida e adotada pela escola no cotidiano (não necessariamente nas ATPC). Na análise do referido professor, tais concepções são inconciliáveis. Além disso, fica evidente que há, expressa em sua fala, uma descrença com relação às práticas preconizadas pela Secretaria - "a coisa vai do nada para o lugar nenhum" -, exigindo que o professor baseie-se no bom senso para realizar o trabalho possível.

Portanto, os dados confirmam que, mesmo pressionando o trabalho docente a se ajustar à sua lógica, as políticas implementadas na rede pública paulista, sobretudo aquelas voltadas à avaliação externa, não são aceitas sem resistência por parte dos professores e da escola, levando-os a desenvolver estratégias de trabalho. Para Birgin (2000), as estratégias podem ser entendidas como ações que os sujeitos desenvolvem para manter ou melhorar o trabalho em diferentes cenários. Segundo a autora, as estratégias resultam, no espaço escolar, do entrecruzamento das histórias e demandas concretas dos sujeitos e das regulações postas pelo Estado. Dessa forma, é preciso admitir que a associação entre acompanhamento sistemático de avaliações, resultados públicos de resultados e bonificação produz efeitos sobre o trabalho pedagógico das escolas e sobre o modo como os professores compreendem e justificam os resultados de seu trabalho.

A escola estudada parece estar, aos poucos, incorporando a ideia bastante corrente nas políticas de natureza neoliberal 
de que cabe a ela (e somente a ela) agir em função da melhoria dos índices gerados pela avaliação externa, a despeito das demandas e escolhas pedagógicas estabelecidas coletivamente. Como discutido por Hypolito (2010), o que era dever do Estado passa a ser encarado como responsabilidade do professor, identificando-se uma descentralização da evidente crise educacional. Também a diretora da escola, ao final da reunião de "Reflexão sobre o SARESP", faz um esforço de tentar evidenciar que os dados gerados por essa avaliação podem servir à escola, na medida em que podem possibilitar certa reflexão a respeito da aprendizagem dos alunos, mas acaba por chamar para a escola a responsabilidade de agir em função da melhoria da aprendizagem dos alunos (e, nessa lógica, a melhoria do Idesp):

\begin{abstract}
Gente quando falamos da discussão do SARESP, o que é importante? Os dados são importantes para nortear alguma coisa, mas eles não devem ser o mais importante, por quê? Um dado é uma informação e nessa informação, o que eu vou fazer com ela? Por isso que se pensa nas ações, por causa disso, para que serve? Às vezes a gente gasta tanto tempo discutindo que foi isso em português, foi esse dado (que é interessante e a gente tem que ter o conhecimento sim), mas o que essa informação, o que esses dados estão gerando, o que eu vou fazer com isso? E é o que a escola tem que ver, o que vai fazer com essas dificuldades, tem que fazer ações em funções desses dados, para que possa alcançar essa aprendizagem do aluno.
\end{abstract}

A manifestação da diretora encontra respaldo na constatação feita por Duarte (2011) que, por sua vez, destaca que o professor, na lógica das avaliações e do desempenho, passa a preocupar-se não apenas com sua atuação em sala de aula, mas também com os resultados do processo de ensino que serão avaliados por sistemas que desconsideram as condições concretas de trabalho às quais estão submetidos.

Ora, é evidente que os professores devem responsabilizar-se pelos resultados de suas atividades, isso não negamos, no entanto, desconsiderar que as condições de trabalho precárias dos professores na rede pública estadual paulista 
dificultam a realização de um trabalho de qualidade é negar o contexto mais amplo no qual a escola está inserida. A própria realização do trabalho docente coletivo, tempo e espaço que deveriam ser privilegiados na organização pedagógica das escolas, é fortemente afetada pelas condições de trabalho, tais como a rotatividade e a presença de contratos precários, além das exigências postas pelas políticas educacionais que burocratizam e direcionam as atividades propostas.

Assim, concordamos com Duarte (2011) quando afirma que implementar mudanças positivas no trabalho docente depende, em grande parte, da "boa vontade" dos professores, ou seja, de que eles se prontifiquem a levar mais trabalho para casa, a estar na escola em períodos nos quais não estão sendo remunerados, a elaborar avaliações a partir de novos modelos, a elaborar relatórios, enfim, a assumir tarefas com condições que não estão dadas na rede pública. Para além das atividades de adaptação às exigências dos sistemas de avaliação, as propostas de trabalho mais significativas na escola pesquisada, como o uso de jogos, projetos de leitura, confecção de fanzines, Feira Cultural, etc., muito provavelmente, extrapolaram os corredores da escola e a sala dos professores, sendo planejadas e preparadas fora do ambiente escolar, invadindo a vida privada dos docentes (DUARTE, 2011). É importante registrar que grande parte do tempo do trabalho docente coletivo remunerado que poderia ser dedicado a essas atividades, como se pode observar, foi empregado na preparação do Saresp.

Vale destacar que, em se tratando de políticas públicas voltadas à educação, não poderíamos depender da boa vontade de pessoas que se disponham (quase de forma missionária como ainda pressupõe certa concepção jesuítica da docência) a criar condições para a realização de seu próprio trabalho. A oferta de condições adequadas de trabalho deveria ser dever primeiro do Estado.

Nesse sentido, observamos que a pressão sofrida pelas escolas públicas estaduais paulistas, como é o caso do locus desta pesquisa, de corresponder às expectativas para atingir determinados patamares e índices que pouco dizem a respeito da qualidade do trabalho desenvolvido na escola se faz sem a devida contrapartida do poder público. O Saresp, 
o Idesp e, consequentemente, o bônus mérito são instrumentos que têm grande centralidade nas práticas escolares, uma vez que provocam evidentes alterações no trabalho docente ao instituir a competitividade e a decorrente preocupação com o desempenho, desconsiderando as condições efetivas que os professores têm para a realização de seu trabalho (BARBOSA; FERNANDES, 2013). Na mesma direção, Hypolito (2010) destaca que a reestruturação educativa da qual essas avaliações são parte não apenas modifica o currículo das escolas, mas também desencoraja o trabalho coletivo e induz, cada vez mais, ao trabalho individual:

O formato de identidade profissional que vem conformando
o trabalho docente envolve o reconhecimento de que as ha-
bilidades docentes derivam da experiência, de modo que a
gestão da sala de aula, as metodologias e todas as ações de
ensino são decisões individuais. Nesse sentido, a autonomia
individual é valorizada, mesmo que o discurso contemple
formas de colaboração. (HYPOLITO, 2010, p. 1345)

Assim, o que podemos evidenciar, nos limites desse artigo, é que as avaliações externas que responsabilizam os professores sem que efetivamente estes possam participar de sua elaboração podem afetar o trabalho docente coletivo como instância de discussão do PPP da escola e, consequentemente, a organização/articulação do processo educativo. As repercussões não podem ser previstas ou controladas, mas toda a comunidade escolar é afetada.

\section{CONSIDERAÇÕES FINAIS}

A produção acadêmica, como já mencionado, vem apontando os efeitos das avaliações externas sobre o currículo, a gestão e a organização do trabalho pedagógico das escolas. De forma semelhante, nossa pesquisa evidencia que há repercussões sobre o trabalho docente coletivo nos espaços e tempos das ATPC, que se afastam de sua dimensão formativa e articuladora. Tal fato afeta a organização do PPP, instrumento privilegiado para o fortalecimento da identidade e autonomia da escola, que fica secundarizado diante da 
necessidade posta à escola de adaptar-se à lógica de resultados das avaliações externas.

Assim, o esforço de construção de um trabalho coletivo no interior da escola pode se tornar esvaziado de sentido pela pressão externa exercida por políticas de avaliação em larga escala que pouco dizem sobre a qualidade efetiva do trabalho desenvolvido na escola. Os avanços identificados na forma como os professores refletem sobre suas práticas a partir do trabalho desenvolvido coletivamente não são passíveis, por exemplo, de serem captados pelos mecanismos de avaliação em vigor na rede paulista de ensino. Da mesma forma, os sistemas de avaliação não consideram as experiências inovadoras de trabalho e nem mesmo as aprendizagens manifestas em relação a conteúdos não presentes em sua matriz de elaboração.

Dias-da-Silva e Fernandes (2006), ao alertar para o perigo da apropriação ideológica do discurso acerca da importância do trabalho coletivo na escola por parte dos idealizadores de nossas políticas educacionais, destacam que uma das armadilhas que podem atrapalhar o desenvolvimento de um trabalho coletivo na escola pública atual é a expectativa de que, por meio da organização coletiva, os problemas da escola sejam resolvidos de forma mágica e se alcance o sucesso esperado pelas políticas de natureza neoliberal, desconsiderando outros tantos resultados positivos que podem decorrer do trabalho coletivo.

O trabalho coletivo e o PPP, bandeiras presentes no movimento de luta por uma escola de fato democrática, foram apropriados por políticas calcadas na performatividade. Tais políticas estrategicamente desorganizam o coletivo escolar, fragilizando o "corpo" docente. Ao estabelecer metas por etapas de escolaridade, a SEE-SP contribui para o rompimento do sentimento de classe e desencoraja as possibilidades de realização de um trabalho docente coletivo entre os diferentes níveis de ensino atendidos pela escola.

Os resultados obtidos nas avaliações tornam-se condições para premiação ou punição. Além de não receber o bônus mérito, a escola passa a ser controlada e fiscalizada pela Diretoria de Ensino, sendo quase atitude heroica fugir às exigências de adaptação e conformação postas pelo sistema. Dessa forma, as propostas inovadoras de trabalho expressas 


\section{no PPP passam a ser atitudes marginais, uma subversão da ordem padronizadora das avaliações externas que levam ao treinamento dos alunos para os testes.}

\section{REFERÊNCIAS}

AMARO, Ivan. Avaliação externa da escola: repercussões, tensões e possibilidades. Estudos em Avaliação Educacional, São Paulo, v. 24, n. 54, p. 32-55, jan./abr. 2013.

BALL, Stephen J. Reformar escolas/reformar professores e os terrores da performatividade. Revista Portuguesa de Educação, Braga, Portugal, v. 15, n. 2, p. 3-23, 2002.

BARBOSA, Andreza; FERNANDES, Maria J. S. O pagamento por desempenho no contexto das reformas educacionais paulistas. Comunicações, Piracicaba, n. 2, p. 45-59, jul./dez. 2013.

BARBOSA, Liliane C. M.; VIEIRA, Lívia F. Avaliações externas estaduais: possíveis implicações para o trabalho docente. Revista e-Curriculum, São Paulo, v. 11, n. 2, p. 409-433, ago. 2013.

BIRGIN, Alejandra. Novas regulações do trabalho docente: o caso da reforma argentina. Cadernos de Pesquisa, São Paulo, n. 111, p. 95-113, dez. 2000.

BONAMINO, Alícia; SOUSA, Sandra Z. Três gerações de avaliação da educação básica no Brasil: interfaces com o currículo da/na escola. Educação e Pesquisa, São Paulo, v. 38, n. 2, p. 373-388, abr.|jun. 2012.

CARVALHO, Cynthia P.; OLIVEIRA, Ana C. P.; LIMA, Maria F. M. Avaliações externas: tensões e desafios para a gestão escolar. Estudos em Avaliação Educacional, São Paulo, v. 25, n. 59, p. 50-76, set./dez. 2014.

CHARLOT, Bernard. O professor na sociedade contemporânea: um trabalhador da contradição. Revista da FAEEBA - Educação e Contemporaneidade, Salvador, v. 17, n. 30, p. 17-31, jul./dez. 2008.

CUNHA, Renata C. O. B.; OMETTO, Cláudia B. C. N. O trabalho coletivo na escola: o projeto político-pedagógico como pauta de formação. Educação, Porto Alegre, v. 36, n. 3, p. 402-411, set./dez. 2013.

DIAS-DA-SILVA, Maria H. G. F.; FERNANDES, Maria J. S. As condições de trabalho dos professores e o trabalho coletivo: mais uma armadilha das reformas educacionais neoliberais? In: SEMINÁRIO DA REDE LATINOAMERICANA DE ESTUDOS SOBRE TRABALHO DOCENTE - REDE ESTRADO, 6 ., 2006, Rio de Janeiro. Anais... Rio de Janeiro: Rede Estrado, 2006. 1 CD-ROM.

DIAS SOBRINHO, José. Avaliação educativa: produção de sentidos com valor de formação. Avaliação, Campinas, v. 13, n. 1, p. 193-207, mar. 2008.

DUARTE, Adriana. M. C. Políticas educacionais e o trabalho docente na atualidade: tendências e contradições. In: OLIVEIRA, Dalila A.; DUARTE, Adriana M. C. (Org.). Políticas públicas e educação: regulação e conhecimento. Belo Horizonte: Fino Traço, 2011. 
FERRAROTTI, Franco. Sobre a autonomia do método biográfico. In: NÓVOA, Antonio; FINGER, Matthias (Org.). 0 método (auto)biográfico e a formação. Natal: EDUFRN; São Paulo: Paulus, 2010. p. 31-58.

GIOVANI, Luciana M. Do professor informante ao professor parceiro: reflexões sobre o papel da universidade para o desenvolvimento profissional de professores e as mudanças na escola. Caderno Cedes, Campinas, v. 19, n. 44, abr. 1998.

HYPOLITO, Álvaro M. Políticas curriculares, Estado e regulação. Educação e Sociedade, Campinas, v. 31, n. 113, p. 1337-1354, out./dez. 2010.

LIMA, Licínio. Avaliação, competitividade e hiperburocracia. In: ALVES, Maria P.; KETELE, Jean-Marie (Org.). Do currículo à avaliação, da avaliação ao currículo. Porto: Porto, 2011. p. 71-82.

Elementos de hiperburocratização da administração educacional. In: LUCENA, Carlos; SILVA JÚNIOR, João R. (Org.). Trabalho e educação no século XXI: experiências internacionais. São Paulo: Xamã, 2012. p. 129-158.

LIMA, Marcos W. As exigências de performatividade e seus impactos na identidade dos diretores escolares: município de Contagem-MG. 2011. 196 f. Dissertação (Mestrado em Educação) - Faculdade de Educação, Universidade Federal de Minas Gerais, Belo Horizonte, 2011.

NOVAES, Luiz C. Os impactos da avaliação externa sobre o trabalho de professores na rede estadual paulista. Roteiro, Videira, SC, v. 39, n. 2, p. 283-310, jul./dez. 2014.

OLIVEIRA, Dalila A. Trabalho docente. In: OLIVEIRA, Dalila A.; DUARTE, Adriana M. C.; VIEIRA, Lívia M. F. Dicionário: trabalho, profissão e condição docente. Belo Horizonte: UFMG/Faculdade de Educação, 2010. CD-ROM.

ROCKWELL, Elsie; EZPELETA, Justa. A escola: relato de um processo inacabado de construção. Currículo sem Fronteiras, Rio de Janeiro, v. 7, n. 2, p. 131-147, jul./dez. 2007.

SÃO PAULO (Estado). Lei Complementar n. 909, de 28 de dezembro de 2001. Institui o Bônus Mérito às classes de docentes do Quadro do Magistério e dá outras providências. Disponível em: <http://www.legislacao.sp.gov.br/ dg280202.nsf|...\$\$FILE/909.doc>. Acesso em: 30 abr. 2015.

Lei Complementar n. 1.078, de 17 de dezembro de 2008. Institui Bonificação por Resultados - BR, no âmbito da Secretaria da Educação, e dá providências correlatas. Disponível em: <http:// www.legislacao.sp.gov.br/ dg280202.nsf/.../\$FILE/C-1078.doc>. Acesso em: 30 abr. 2015.

SÃO PAULO (Estado). Secretaria de Educação. Coordenadoria de Gestão de Educação Básica - CGEB. Orientações para o planejamento escolar 2014. 2014. Disponível em: <http://www.educacao.sp.gov.br/a2sitebox/arquivos/ documentos/669.pdf>. Acesso em: 30 abr. 2015.

SÃO PAULO (Estado). Secretaria de Educação. Coordenadoria de Gestão de Educação Básica - CGEB. Coordenadoria de Informação, Monitoramento e Avaliação Educacional - CIMA. Resolução SE n. 45, de 10 de julho de 2013. Dispõe sobre a realização das provas de avaliação relativas ao Sistema de 
Avaliação de Rendimento Escolar do Estado de São Paulo - SARESP/2013.

2013. Disponível em: <http://file.fde.sp.gov.br/saresp/saresp2013/

Arquivos/03_Resolução_45_SARESP_2013.pdf>. Acesso em: 30 abr. 2015.

SOUSA, Sandra Z. Possíveis impactos das políticas de avaliação no currículo escolar. Cadernos de Pesquisa, São Paulo, n. 119, p. 175-190, jul. 2003.

SOUSA, Sandra Z.; MAIA, Márcia M. V.; HAAS, Célia M. Avaliação, índices e bonificação: controvérsias por dados da rede estadual paulista. Estudos em Avaliação Educacional, São Paulo, v. 25, n. 58, p. 188-209, maio/ago. 2014.

SOUSA, Sandra Z.; OLIVEIRA, Romualdo Portela. Sistemas estaduais de avaliação: uso dos resultados, implicações e tendências. Cadernos de Pesquisa, São Paulo, v. 40, n. 141, p. 793-822, set./dez. 2010.

VEIGA, Ilma P. A. A escola em debate: gestão, projeto político-pedagógico e avaliação. Revista Retratos da Escola, Brasília, DF, v. 7, n. 12, p. 159-166, jan./jun. 2013.

. Inovações e projeto político-pedagógico: uma relação regulatória ou emancipatória? Cadernos CEDES, Campinas, v. 23, n. 61, p. 267-281, dez. 2003.

\section{RENATA CRISTINA OLIVEIRA BARRICHELO CUNHA}

Professora do Programa de Pós-Graduação em Educação da Universidade Metodista de Piracicaba (Unimep), Piracicaba, São Paulo, Brasil

reccunha@unimep.br

\section{ANDREZA BARBOSA}

Professora do Programa de Pós-Graduação em Educação da Universidade Metodista de Piracicaba (Unimep), Piracicaba, São Paulo, Brasil andrezab27@gmail.com

MARIA JOSÉ DA SILVA FERNANDES

Professora do Programa de Pós-Graduação em Educação Escolar da Faculdade de Ciências e Letras da Universidade Estadual Paulista "Júlio de Mesquita Filho” (Unesp), Araraquara, São Paulo, Brasil mjsfer@fc.unesp.br 
